\title{
EUROSURVEILLANCE ACHIEVEMENTS IN 2008 AND CHALLENGES FOR 2009
}

\author{
Eurosurveillance editorial team (eurosurveillance@ecdc.europa.eu)1 \\ 1. European Centre for Disease Prevention and Control, Stockholm, Sweden
}

2008 was yet another year of major innovations for Eurosurveillance. Since January 2008, Eurosurveillance has been published once a week online with short, rapid communications as well as longer papers on the surveillance, prevention and control of communicable diseases. In April we launched a new readerfriendly website with modern design and functionalities such as easy navigation between articles, display of related articles and improved search function.

A continuing rise in the number of subscribers to over 14,000 by the end of 2008 (see Figure 1) and an increasing number of submissions from European scientists as well as from experts from outside Europe proves that our efforts to raise the journal's scientific credibility have been successful. The new subscriptions in 2008 covered 121 different countries. The majority came from Europe, but many also from the Unites States (181), Canada (73) and Australia (52).

The geographical focus of the journal remains Europe even if we also publish articles from other countries if the topic is relevant for Europe. Figure 2 shows the wide distribution of countries from which we received contributions in 2008. We published 128 peer-reviewed rapid communications and 107 peer-reviewed long articles, additional 56 items were editorials, news, letters and meeting reports.
The possibility of peer-reviewed extremely rapid communications (published within as little as 24 to 48 hours) remained a unique feature of Eurosurveillance in 2008. As in previous years, they facilitated the rapid exchange of information for public health action, and in several cases contributed to the control of international outbreaks. Their impact was reinforced through the fact that the International Society for Infectious Diseases' Program for Monitoring Emerging Diseases (ProMED-mail) picked up at least one Eurosurveillance article per week for their world-wide mailings.

Among the long articles published in 2008, of particular value for the scientific community were the review articles covering areas from antimicrobial resistance in Europe to vaccination for seasonal influenza and tick-borne encephalitis in Europe. In 2008 we published eight special issues on meningococcal disease, tuberculosis, immunisation, molecular typing, hepatitis $B$ and $C$, testing for recent human immunodeficiency virus (HIV) infections, seasonal influenza vaccination, antimicrobial resistance. Six Euroroundup articles covered the surveillance of viral meningitis and encephalitis, human salmonella infections acquired through contact with exotic pets, monitoring of congenital toxoplasmosis, hantavirus infections, managing patients with meningococcal disease and their contacts and Clostridium difficile 027.
F I G U R E 1

Number of Eurosurveillance subscriptions in 2008 as of 18 December $2008(n=14,204)$

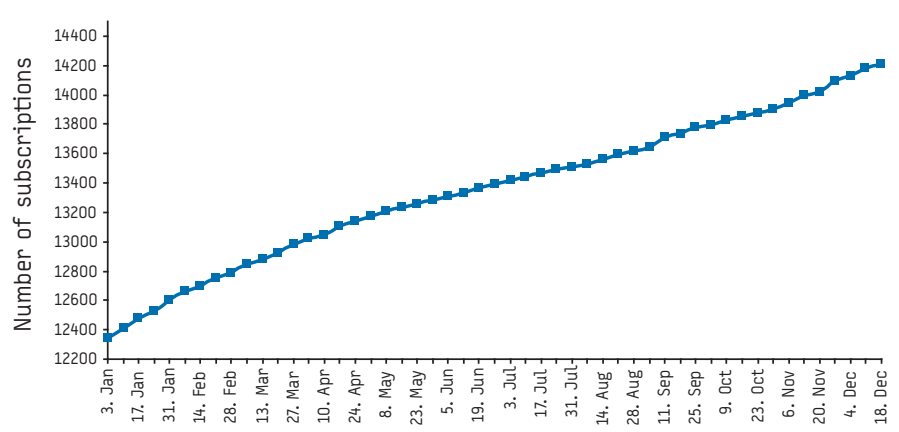

F I G U R E 2

Articles published in Eurosurveillance, in 2008, by country of origin $\left(n=291^{\star}\right)$

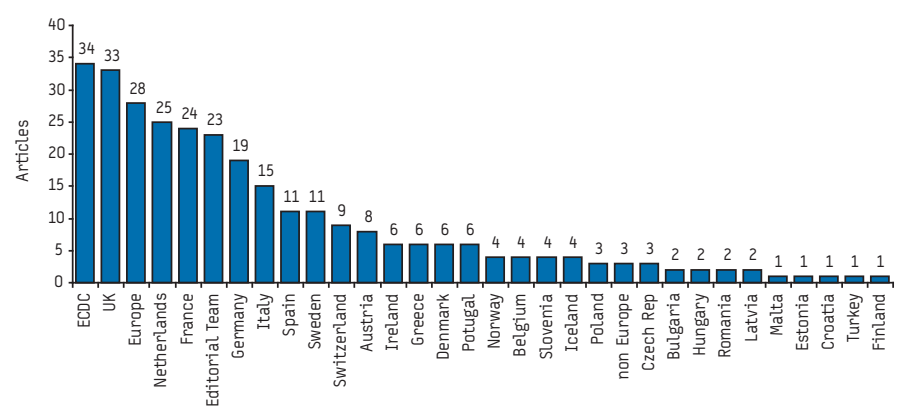

* redundant counting when two or three countries involved; counted as "Europe" when more than three countries involved. 
All this could not have been achieved without the continued support of our Associate Editors and Editorial Board members and, last but not least, our authors and readers to all of whom we are grateful. Furthermore, we thank all experts who dedicated their time to review articles for us, and we are obliged to those who provided us with helpful advice to guarantee the high quality of our publications. In this week's issue we want to acknowledge this help by publishing a list of otherwise invisible peer-reviewers in 2008.

What has been accomplished in 2008 will stimulate our work in 2009. We will continue to attract the most relevant high quality articles in the field and to provide our readers with timely information about important outbreaks and developments in infectious diseases. Attracting even more readers and contributors and strengthening our impact are additional challenges for 2009. We will persist in our vigilance to contribute to the prevention and control of infectious diseases in Europe and are looking forward to collaborating with you towards this goal.

This article was published on 8 January 2009

Citation style for this article: Eurosurveillance editorial team. Eurosurveillance achievements in 2008 and challenges for 2009. Euro Surveill. 2009;14(1):pij=19084 Available online: http://www.eurosurveillance.org/ViewArticle.aspx?ArticleId=19084 